\title{
0 irracionalismo na teoria do conhecimento de Schopenhauer e na epistemologia de Paul Feyerabend*
}

\author{
The irrationalism in the theory of Schopenhauer's knowledge and Paul \\ Feyerabend's epistemology
}

\author{
Antunes Ferreira da Silva \\ Mestre em Filosofia pela UFPB \\ Professor da Universidade Federal de Campina Grande (UFCG) \\ Thalyta de Paula Pereira Lima \\ Doutora em Sociologia pela UFPB \\ Professora da Universidade Federal de Campina Grande (UFCG)
}

\begin{abstract}
Resumo: Este artigo pretende analisar a origem do irracionalismo presente na teoria do conhecimento de Schopenhauer e a epistemologia de Paul Feyerabend. Por um lado, Schopenhauer, atacando diretamente a filosofia hegeliana, defende que, por ser uma atividade secundária, não é possível à racionalidade humana conceber, entender ou explicar o real, por ser constituído de algo que, ao menos abstratamente sob a forma de conceitos, não pode ser abstraído, mas tão somente intuído. Ele defende uma espécie de conhecimento espontâneo e, com isto, demonstra o quanto inócua é a tentativa racional de estabelecer caminhos ou métodos que o possibilitem. Por outro lado, Feyerabend postula que as grandes descobertas científicas, por surgirem na história e levando em consideração o contexto cultural de cada povo, não foram provocadas, em sua maioria, pela observância de métodos rigorosos e definidos aprioristicamente, mas especialmente descobertos para dado campo de estudo. Sendo assim, não seria possível estabelecer métodos universais e absolutos que possam conduzir a racionalidade humana ao conhecimento do real. E quando tal acontece, estes nada mais seriam do que imposições que objetivam muito mais a manutenção das relações de poder do que a verdadeira busca do real. Ora, embora sur-
\end{abstract}

Abstract: This article intends to analyze the origin of irrationalism present in the theory of knowledge of Schopenhauer and Paul Feyerabend's epistemology. On one side, Schopenhauer, directly attacking the hegelian philosophy, it claims that, as a secondary activity, it is not possible to human rationality conceive, understand or explain the real, to be constituted by something that, at least abstractly in the form of concepts, can not be abstracted, but only intuited. He defends a kind of spontaneous knowledge and, therefore, demonstrates how innocuous is the rational attempt to establish ways or methods that make it possible. On the other side, Feyerabend postulates that the great scientific discoveries, by coming in history and taking into consideration the cultural context of each people, they were not caused, in their majority, for the observance of rigorous methods and defined a priori, but especially discovered for a given field of study. Thus, it would not be possible to establish universal and absolute methods that could lead to human rationality to the knowledge of real. And when this happens, these are nothing more than impositions that aims much more maintenance of power relations than true search of real. Although arisen in different ways and contexts, both conclude that the reason is se-

\footnotetext{
* Comunicação apresentada durante o VII Colóquio Internacional Schopenhauer, ocorrido na Universidade Federal da Bahia (UFBA), em Salvador, de 26 a 30 de outubro de 2015.
} 
gidas em meios e contextos diferentes, ambos chegam à conclusão de que a razão é secundária e que, portanto, não se pode confiar nela para o progresso do conhecimento.

Palavras-chave: Razão; Vontade; Método; Irracionalismo. condary and therefore, you can not trust on them for the progress of knowledge.

Keywords: Reason; Will; Method; Irrationalism. 


\section{Introdução}

A inquietação com tal problemática teve três momentos de nascedouro:

0 primeiro momento data do encontro da Sociedade Interamericana de Filosofia, nesta cidade de Salvador, entre os dias 07 a 11 de outubro de 2013, quando pude assistir, em mesa mediada pelo Prof. Jarlee Salviano (UFBA), a comunicação de Edgar Serna Ramírez, da Facultad de Filosofía y Letras da Universidad Nacional Autónoma do México (UNAM), com o seguinte tema: o papel que tem a intuição e o descobrimento na epistemologia de Schopenhauer (no original, El papel que tiene la intuición y el descubrimiento em la epistemoligía de Schopenhauer). Em tal estudo, a cuja versão integral não tive acesso, o autor menciona as relações entre as epistemologias de Schopenhauer e os filósofos da ciência que antecederam Paul Feyerabend, como Karl Popper, Thomas Kuhn e Imre Lakatos.

O segundo momento data de pesquisa desinteressada no Dicionário de Filosofia, de Nicola Abbagnano, quando encontrei, já inquieto com uma possibilidade de defesa de um certo irracionalismo em Schopenhauer, a seguinte citação:

IRRACIONALISMO (ai. Irrationalismus). Termo com que, em italiano e alemão, são designadas as filosofias da vida ou da ação, que, como p. ex a de Schopenhauer, consideram o mundo como manifestação de um princípio não racional (v. AÇÃO, FILOSOFIA DA; VIDA) ${ }^{1}$.

O terceiro remonta ao período em que ministrava aulas na disciplina Filosofia da Ciência, quando, estudando junto aos alunos as obras de Paul Feyerabend, percebia nítida proximidade, senão nos argumentos, pelo menos na conclusão à qual chegam, cada um ao seu tempo, os dois filósofos ora investigados, mesmo que sumariamente. As discussões sobre tal proximidade foram renovadas por minha dileta amiga e colega de Universidade, a Profa. Dra. Thalyta de Paula, que comigo é coautora deste texto, uma vez que, embora da área de Sociologia, o cientificismo constitui um dos seus focos de pesquisa. E desde que ingressei no

${ }^{1}$ ABBAGNANO, N. Dicionário de filosofia, p. 586, grifos do autor. 
magistério daquela universidade, nos detemos, quase como que em devaneios, sobre tais assuntos.

\section{A teoria do conhecimento em Schopenhauer e o caráter secundário da razão}

Schopenhauer, como sabemos, constituiu um pensamento filosófico definido, por ele, como o único e autêntico continuador de Kant. A partir de sua teoria do conhecimento, condensada basicamente em sua tese doutoral Sobre a quádrupla raiz do princípio de razão suficiente (PR - 1813) e, posteriormente, em sua obra central $O$ mundo como vontade e como representação (MVR - 1818), surge, em Schopenhauer, um novo campo de investigação sobre a finitude do conhecimento humano, que fora antes proposto por Kant, quando este verificou os limites da razão.

Pretende-se expor, pois, três posicionamentos para, ao fim, argumentar, ao menos como possibilidade de se entender a filosofia schopenhaueriana como irracionalista: 1- a constatação da Vontade não possuir razão alguma; 2- o status secundário do intelecto em detrimento da conhecida primazia da Vontade; 3 reforçar este último ponto com a distinção entre conhecimento intuitivo e conhecimento abstrato e supervalorização do primeiro em detrimento da desvalorização do segundo.

\subsection{Sobre a irracionalidade da Vontade}

Schopenhauer se volta à fundamentação de uma filosofia imanente, uma vez que se mostra veementemente contra a filosofia de sua época, a saber: o hegelianismo e a defesa do absoluto. Deste modo, seu organismo filosófico frisa a existência e a submissão de tudo à Vontade, ímpeto cego e irracional, algo idêntico a um princípio natural de existência, que, por não possuir qualquer razão, faz do viver um eterno sofrer e da existência uma completa e sempre fracassada luta por matéria. 
"Que é a coisa-em-si? - Nossa resposta foi: a VONTADE"2. A Vontade surge como "a verdade filosófica por excelência, [...] o segredo do ser"3, a coisa-em-si, o númeno kantiano.

Reconhecerá a mesma vontade como essência mais íntima não apenas dos fenômenos inteiramente semelhantes ao seu, ou seja, homens e animais, porém, a reflexão continuada o levará a reconhecer que também a força que vegeta e palpita na planta, sim, a força que forma o cristal, que gira a agulha magnética para $o$ pólo norte, [...] a própria gravidade que atua poderosamente em toda matéria, [...] tudo isso é diferente apenas no fenômeno, mas conforme sua essência em si é para se reconhecer como aquilo conhecido imediatamente de maneira tão íntima e melhor que qualquer outra coisa e que, ali onde aparecer de modo mais nítido, chama-se VONTADE4.

A Vontade é, pois, una, livre, indiferente, independente da consciência que dela temos, da causalidade, das formas a priori do conhecimento (espaço e tempo), portanto incognoscível, pois não obedece a nenhum padrão fenomênico, ou seja, ela "não se submete à forma mais geral de todas as representações, que é a de ser um objeto para um sujeito"5. Nas palavras de Schopenhauer:

Ela mesma (a Vontade) (...) é completamente diferente (...) (dos seus fenômenos) e, embora em sua aparição esteja integralmente submetida ao princípio de razão como forma de representação, ainda assim nunca é remissível a esta forma e, por conseguinte, não é etiologicamente explicável até o seu fundo, não podendo ser por completo fundamentada 6 .

\subsection{Primado da Vontade sobre o intelecto}

Com o estabelecimento da Vontade como coisa-em-si e um princípio irracional, Schopenhauer destitui a importância do intelecto, pois a este resta apenas a função de estar subordinado à Vontade. Em outras palavras, há a evidenciação do primado da Vontade sobre o intelecto7. Schopenhauer explicita

\footnotetext{
2 SCHOPENHAUER, A. MVR I, § 24, p. 140.

${ }^{3}$ PERNIN, Marie-José. Schopenhauer: decifrando o enigma do mundo, p. 72-73.

${ }^{4}$ SCHOPENHAUER, A. MVR I, § 21, p. 128.

${ }^{5}$ CACCIOLA, M.L.M.O. Schopenhauer e a questão do dogmatismo, p. 53.

${ }^{6}$ SCHOPENHAUER, A. MVR I, § 24, p. 142.

${ }^{7}$ Cf. BARBOZA, J. A metafísica do belo de Arthur Schopenhauer, p. 33.
} 
sua doutrina do primado da Vontade, comparando, para tanto, a Vontade ao sultão que, depois de curtido seu ócio, acena como lhe aprouver às conclusões do intelecto. Christopher Janaway afirma: "o intelecto é consciente, constituindo a nossa janela para o mundo, porém a força motriz que nos leva ao lugar para o qual vamos se acha num plano mais profundo de nossa pisque, no interior do organismo que também somos"8 que chamamos Vontade.

Quando percorremos a série dos seres em sentido descendente, vemos o intelecto cada vez mais débil e incompleto: mas de maneira alguma observamos uma correspondente degradação da vontade. [...] [0 intelecto] [...], como secundário e atado ao órgão corporal, possui inumeráveis graus de completude e é em geral essencialmente limitado e incompleto. [...] Se o intelecto apresenta à vontade um simples objeto intuível; então ela expressa de imediato o seu agrado ou desagrado sobre ele: o mesmo se dá quando o intelecto laboriosamente ponderou e ruminou, para, a partir de numerosos dados, por meio de combinações difíceis, finalmente produzir o resultado que melhor parece adequar-se aos interesses da vontade; só que nesse ínterim a vontade descansava ociosa, para então, após o resultado alcançado, entrar em cena igual a um sultão no divã para apenas de novo expressar o seu monótono agrado ou desagrado que decerto podem variar segundo diversos graus mas em sua essência permanecem sempre os mesmos 9 .

Somos essencialmente Vontade, o intelecto é apenas um apêndice que nos foi acrescido. A harmonia mínima que reina no mundo não é efeito do governo do intelecto, como julgava o idealismo alemão, do qual Schopenhauer foi contemporâneo. "A vontade nunca obedece ao intelecto. A vontade se detém na proposição desse ministro que lhe convém, segundo a natureza do seu caráter, sem que nunca o conhecimento dos erros passados venha mudar a direção fundamental da conduta"10.

Também a usual FRAQUEZA E IMPERFEIÇÃO do intelecto, tal qual ela revela-se na falta de juízo, limitação, perversidade e insensatez da maioria dos seres humanos seria completamente inexplicável se o intelecto não fosse algo secundário ${ }^{11}$.

\footnotetext{
${ }^{8}$ Cf. JANAWAY, C. Schopenhauer, p. 73.

${ }^{9}$ SCHOPENHAUER, A. MVR II, p. 250-251.

${ }^{10}$ PERNIN, Marie-José. Schopenhauer: decifrando o enigma do mundo, p. 98.

${ }^{11}$ SCHOPENHAUER, A. MVR, II, p. 259, grifos do autor.
} 


\subsection{Distinção entre conhecimento intuitivo e conhecimento abstrato}

Schopenhauer faz distinção entre representações intuitivas e representações abstratas. Em sua Crítica da filosofia kantiana, chega a afirmar que um dos grandes erros de Kant seria confundir o conhecimento intuitivo com o conhecimento abstrato, conforme percebe-se nas palavras do filósofo:

É assombroso como Kant [...] após [...] levar em consideração o conhecimento intuitivo só na matemática, negligencia por completo o conhecimento intuitivo restante, no qual o mundo coloca-se perante nós, e atém-se tão somente ao pensamento abstrato; o qual , entretanto, recebe toda a sua significação e valor primeiro do mundo intuitivo, infinitamente mais significativo, mais universal, mais rico em conteúdo que a parte abstrata de nosso conhecimento. [...] Nasce daí uma irremediável confusão ${ }^{12}$.

O entendimento se caracteriza por ser a atividade básica de apreensão da matéria em suas relações de causalidade, característica que não é prerrogativa exclusiva do homem, pois podemos sem muita dificuldade empiricamente constatar, mesmo não nos mesmos graus, que alguns animais conseguem inferir algumas relações de causa e efeito, ou seja, algumas apreensões da matéria13.

Não é a ausência de entendimento que nos distingue dos animais, pois, como vimos, estes possuem algumas formas de entendimento, mas sim pela existência de razão nos humanos, a capacidade de formar conceitos (representações abstratas) e, consequentemente, de possuir suas prerrogativas: a linguagem, a ciência, direito etc, pois, livres do jugo das necessidades momentâneas, podemos ponderar sobre as coisas passadas afim de formularmos o futuro, sendo, portanto, capazes de deliberar sobre nossas ações.

É esta capacidade de deliberação que fundamenta o que, corroborado pelo entendimento de Jair Barboza14, pode se entender como a abertura do pensamento schopenhaueriano ao otimismo prático ou ao que comumente é chamado de atmosfera de consolo.

\footnotetext{
12 SCHOPENHAUER, A. MVR I, CK, p. 500 e 507.

${ }^{13}$ Cf. CARDOSO, R.C. A ideia de justiça em Schopenhauer, p. 63.

${ }^{14}$ BARBOZA, J. Prefácio. In: SCHOPENHAUER, A. Aforismos para a sabedoria de vida, p. XVI.
} 
Em suma, o mundo é um aglomerado de representações dos múltiplos objetos entendido pelo sujeito, o que torna impensável e absurda uma existência absoluta e em si mesma objetiva, seja ela qual for. Concepção que torna Schopenhauer contrário tanto ao materialismo, que nega o sujeito, reduzindo-o à matéria, quanto ao realismo, segundo o qual a realidade externa se refletiria por aquilo que está em nossa mente, defendendo, pois, o idealismo, nos moldes do idealismo transcendental kantiano.

No arcabouço da filosofia schopenhaueriana, a Vontade é a origem de todo sofrimento ${ }^{15}$. A redenção, portanto, nada mais é do que suplantar esta Vontade (entendida como vontade de vida ou auto-afirmação) o olhar pra além do princípio de individuação (principium individuationis), ou seja, ultrapassar as formas normais do nosso conhecimento abstrato pelo conhecimento intuitivo e puro. Deste modo, “[...] a salvação vem do conhecimento, mas não pelo conhecimento $[\ldots] " 16$.

De fato, “[...] a virtude [...] provém do conhecimento, porém não do conhecimento abstrato, comunicável em palavras"17. 0 conhecimento, pois, que proporciona a possível negação da Vontade, se é que esta negação é realmente possível, é o conhecimento intuitivo, aquele que é adquirido instantaneamente e sem uso de abstrações nem formação de conceitos e, de certo modo, fora dos termos da razão (tempo espaço e causalidade).

Sobre esta negação advinda do conhecimento, diversas são as vezes nas quais Schopenhauer a afirma: “[...] conhecimento [que] se lhe torna um QUIETIVO, silenciando e suprimindo todo querer"18. E ainda: "o conhecimento, ao contrário, fornece a possibilidade de supressão do querer, de redenção pela liberdade, de superação e aniquilamento do mundo"19.

O conhecimento intuitivo possui tamanha importância uma vez que é entendido como puro conhecer, ou seja, aquele que possibilita que permaneçamos alheios a todo querer, que nos transforma em "espectadores desinteressados"

${ }_{15}$ Cf. SCHOPENHAUER, A. MVR I, § 56, p. 359 e I, § 57, p. 361.

${ }^{16}$ JANAWAY, C. Schopenhauer, p. 138.

17 SCHOPENHAUER, A. MVR I, § 66, p. 427.

${ }^{18}$ SCHOPENHAUER, A. MVR I, § 56, p. 356, grifo do autor.

${ }^{19}$ SCHOPENHAUER, A. MVR I, § 60, p. 383-384. 
diante dos ditames da Vontade ${ }^{20}$. Um conhecer amplo, que ultrapassa a causalidade, que enxerga o todo, em detrimento das partes figuradas por nossos moldes representativos, uma intelecção que pode evitar as tensões extremas da mente: a alegria desmesurada e a dor atroz, nas palavras de Schopenhauer: "[...] uma visão perfeitamente clara das coisas em seu conjunto e encadeamento [...] [que se torna responsável] por livrar a mente e todo esse engano e suas consequências [...]"21.

Deste modo, Schopenhauer se põe contra a racionalidade, ou pelo menos, lhe nega a importância outrora dada pela Filosofia que o antecedeu, entendida como abstração e consequente formulação de conceitos, que pretende ser a chave mestra para o entendimento das coisas, para a formulação da ciência e a compreensão do mundo e, neste sentido, abre brecha para que sua teoria do conhecimento seja entendida, por vezes, como irracional.

Sendo assim, toma-se a liberdade de discordar, em partes, do que está posto por Jair Barboza na página XVI (16) da apresentação de sua tradução do Mundo como vontade e como representação, quando escreve: "indicar, porém, um princípio irracional do mundo e mostrar o papel secundário da razão na natureza humana não significa ser irracionalista"22.

A isto acrescenta-se que não necessariamente. 0 que também não significa que a esta possibilidade esteja de todo descartada, uma vez que corrobora para esta tese também o fato da descrença schopenhaueriana para com o conhecimento abstrato, e, para usar as palavras do próprio tradutor já citado em sua nota à segunda edição brasileira, quando evidencia elementos pelos quais a teoria schopenhaueriana não teria sido bem aceita no meio acadêmico brasileiro, diz: "sua postura de desconfiança da tradição racionalista de pensamento (e seu estilo científico)" bem como a evidência "do forte contraposicionamento [de Schopenhauer ao projeto cartesiano e iluminista de domínio técnico] que feriu ainda mais o narcisismo de muitos acadêmicos e cientistas cegamente confiantes na faculdade de razão"23.

20 Cf. SCHOPENHAUER, A. MVR I, § 57, p. 363.

${ }^{21}$ SCHOPENHAUER, A. MVR I, § 57, p. 369.

22 BARBOZA, J. Prefácio. In: SCHOPENHAUER, A. Aforismos para a sabedoria de vida, p. XVI.

${ }^{23}$ BARBOZA, J. Prefácio. In: SCHOPENHAUER, A. Aforismos para a sabedoria de vida, p. XVI. 
Deste modo, quando se indica um princípio irracional do mundo, se mostra o papel secundário da razão humana frente às possibilidades de desvelar o real e, com isso, se diminui o poder do instrumental científico (por meio da valorização do conhecimento intuitivo e desvalorização do conhecimento abstrato), pode significar um irracionalismo, quando entende-se por este a teoria que, ao menos genericamente, designa a tese filosófica ou epistemológica que privilegia o exercício da vontade e da individualidade em detrimento da compreensão racional de um mundo objetivo.

\section{Epistemologia em Paul Feyerabend}

Paul Feyerabend dedicou-se especialmente à filosofia da ciência e constituiu um pensamento filosófico conhecido como anarquista. Inicialmente, seguidor de Karl Popper, de quem foi orientando na Escola de Economia de Londres, passou, posteriormente, a criticar a teoria do mestre. Segundo sua tese, não há um método científico universal que pretenda ser a-histórico, nem muito menos regras científico-metodológicas universais. Deste modo, sua filosofia caracteriza-se, essencialmente, em não aceitar um padrão epistemológico e em defender o pluralismo acíclico, de modo que a ciência avança de forma desigual e não progressiva, uma vez que todas as teorias são falíveis por sua própria natureza. Ele, ao defender uma epistemologia anárquica, se mostra contra a epistemologia de sua época, defendida especialmente por Karl Popper (1975), mas também por Thomas Kuhn (2003), de quem Feyerabend foi amigo e adaptou alguns dos termos por ele usados. As principais obras nas quais defende as ideias acima descritas são Contra o método (CM - 1975) e Adeus à razão (AR - 1987), dentre outras.

Os focos principais da pesquisa em filosofia da ciência que o filósofo citado põe em cheque são, especificamente, as ideias de objetividade e de racionalidade, especialmente quando estas constituem o que se pode denominar cientificismo, ou seja, a teoria criada em meados do século XIX que alega ser a ciência, e seus métodos, a única capaz de explicar e provocar a compreensão do mundo. Em outras palavras, a tese de que as ciências naturais e formais possuem primazia sobre qualquer outra forma de conhecimento ou de saber. Afirma Feyerabend: "mais especificamente, irei criticar duas ideias que foram muitas vezes utilizadas 
para tornar a expansão ocidental intelectualmente respeitável - a ideia da Razão e a ideia da Objetividade"24. Em outro momento, chega mesmo a acusar o cientificismo de produtor de sonhos: "um exame de períodos de pesquisa [...] mostra que a ideia de uma ciência que caminha graças à argumentação logicamente rigorosa nada mais é que um sonho"25.

Feyerabend não é o primeiro, na história da filosofia da ciência dos últimos séculos a criticar tal postura científica. Trata-se, na verdade, de uma construção que o precede e da qual ele parece estar no teto, como se fosse o clímax do que outrora seria uma teoria em construção. Ora, as teorias de Thomas Khun (na formulação de que a ciência não é objetiva e universal, uma vez que se serve de paradigmas) e de Karl Popper (de que as descobertas científicas podem facilmente ser falsificadas, uma vez que se mudem os procedimentos contemporâneos de pesquisa ou se mude o paradigma científico vigente) nada mais são do que as gestantes de uma tese que postula o completo descrédito para com a pretensão humana, advinda do positivismo, de que com a razão, isto é, a partir dos procedimentos científicos criados pela racionalidade, a inteligência humana pode entender e compreender todas as coisas. Deste modo, Feyerabend não pode aceitar que se postule padrões que possam ordenar o conhecimento, como afirma: "já mencionei o caso das ciências: elas podem prosseguir de uma maneira ordenada, mas os padrões que ocorrem não são estáveis e não podem ser universalizados" 26 e ainda: "e ser racional ou usar a razão passou a significar usar essas maneiras [de descobrir a verdade independente da tradição cultural de um povo] e aceitar seus resultados"27.

Três são as principais objeções: a primeira diz respeito a uma questão cultural; a segunda versa por uma problematização que envolve a liberdade de pesquisa, ou, dito de outro modo, que envolve um problema ético; a terceira, que ela deve se entendida como um conceito histórico e, portanto, possui passado.

Sobre a primeira objeção, afirma Feyerabend: "a variedade cultural não pode ser domesticada por uma noção formal de verdade objetiva, porque ela

\footnotetext{
${ }^{24}$ FEYERABEND, P. Adeus à razão, p. 12.

25 FEYERABEND, P. Adeus à razão, p. 17.

${ }^{26}$ FEYERABEND, P. Adeus à razão, p. 19.

27 FEYERABEND, P. Adeus à razão, p. 15.
} 
contém uma variedade dessas noções" 28 . Não se pode crer que os critérios criados por uma Europa de tradições ocidentais e de cultura evoluída de um modo específico e distinto das demais sociedades possa impor suas regras de conhecimento, seu modo de entender o mundo aos demais povos do planeta, fazendo-os se passar como os únicos válidos e úteis, portanto, os mais objetivos possíveis. Aliás, até na formação da noção de objetividade influem os traços culturais das sociedades, o que torna tal noção, mesmo sendo de objetividade, não tão objetiva quanto necessário ao seu intento em sê-la.

A segunda objeção versa sobre um problema ético. "Ser racional no sentido formal significa seguir certo procedimento"29, ou seja, significa a criação de um padrão de comportamento e ação que deve ser seguido sempre que se queira alcançar a verdade.

A premissa de que existem padrões de conhecimento e de ação universalmente válidos e aglutinadores é um caso especial de uma crença cuja influência vai muito além do domínio do debate intelectual. Essa crença [...] pode ser formulada dizendo que existe uma maneira certa de viver que o mundo deve aceitar (AR, 2001, p. 18$)^{30}$.

Tal objeção leva em consideração o problema da liberdade. Os princípios gerais não podem abranger todos os elementos geradores que costuma influenciar as grandes conquistas da humanidade, especialmente porque estas não foram garantidas pela simples formulação de uma regra universal, mas porque foram conquistadas não obstante o emprego de lutas e consequentes soluções conciliatórias.

A terceira objeção versa sobre a historicidade de tal caráter universal da ciência e de seus procedimentos. Ou seja, tal critério uma vez identificado em algum momento da história deve ser entendido em relação às circunstâncias que provocaram o seu surgimento. Tal procedimento evita que se traga para a atualidade, sob o foco da universalidade e objetividade, um conhecimento que tenha surgido em dadas circunstâncias que não são mais as atuais. A evolução histórica requer novos procedimentos históricos que se pautem sobre a realidade

\footnotetext{
${ }^{28}$ FEYERABEND, P. Adeus à razão, p. 16.

${ }^{29}$ FEYERABEND, P. Adeus à razão, p. 17.

${ }^{30}$ FEYERABEND, P. Adeus à razão, p. 18.
} 
ora vivida, ao invés de ficar relutando em levantar procedimentos gerados, talvez com êxito ou não, em outros momentos que não o vivido atualmente.

Vejamos as palavras de Feyerabend:

A ciência como empreendimento vivo (ao contrário de ciência como um "corpo de conhecimento") é parte a história. As fórmulas que adornam nossos manuais são parte temporariamente congeladas de atividades que se movem com o fluxo da história. É preciso que sejam descongeladas, conectadas uma vez mais ao fluxo a fim de que sejam compreendidas e produzam resultados ${ }^{31}$.

Deste modo, quando o caráter histórico da ciência é finalmente entendido, talvez seja hora de dizer-lhe adeus:

\begin{abstract}
Alguns pensadores, confusos e abalados pelas complexidades da história, disseram adeus à razão e substituíram-na por uma caricatura; sendo incapazes de esquecer a tradição (e não sendo contrários a um pouco de relações públicas), continuaram a chamar essa caricatura de razão (ou Razão, com "R" maiúsculo, para usar minha própria terminologia). A Razão foi um grande sucesso entre filósofos que não gostam de complexidade e entre políticos (tecnólogos, banqueiros etc.) que não se importam em acrescentar um pouco de classe a sua luta pela dominação do mundo. É um desastre para o resto, isto é, para praticamente todos nós. É hora de lhe dizer adeus ${ }^{32}$.
\end{abstract}

Deste modo, ganha escopo uma teoria, pela qual Feyerabend ficou conhecido como sendo sua postulante, de que o conhecimento é anárquico. Não possui regras universal ou objetivamente válidas, nem poderia ser aceita como única fonte possível do conhecimento. Endossa-se, pois o anarquismo epistemológico. Ou seja, não existem padrões científicos e metodológicas úteis ou livres de exceções que possam guiar o desenvolvimento dos conhecimentos ou o progresso científico. É irrealista e perniciosa a ideia de que a ciência pode ou deve operar de acordo com regras fixas e universais e tal crença se constitui um atentado contra a própria ciência, uma vez que "está claro, então, que a ideia de um método fixo ou de uma teoria fixa da racionalidade baseia-e em uma concepção

31 FEYERABEND, P. Adeus à razão, p. 22.

32 FEYERABEND, P. Adeus à razão, p. 25-26. 
demasiado ingênua do homem e de suas circunstâncias"33, como afirma:

A ciência é um empreendimento essencialmente anárquico: o anarquismo teórico é mais humanitário e mais apto a estimular o progresso do que suas alternativas que apregoam lei e ordem. [...] 0 anarquismo [...] é, com certeza, um excelente remédio para a epistemologia e para a filosofia da ciência ${ }^{34}$.

Deste modo, uma vez que o anarquismo é mais humanitário que qualquer outro procedimento, caem por terra qualquer outro procedimento considerado como válido, correto ou adequado, e, consideradas as circunstâncias nas quais surgem os procedimentos científicos, visto que são sempre históricos e devem ser entendidos em seus respectivos contextos, não sobra outra alternativa senão a desobediência aos princípios sempre que restarem alteradas as circunstâncias que provocaram seu surgimento, afinal “[...] o apelo à razão, ao qual [o intelectual, de um modo geral] sucumbe, não passa de manobra política"35. Em outras palavras, não apenas não seguir aqueles que no passado ficaram, mas ignorá-los definitivamente, adotar as regras que podem sugerir a posição contrária à sugerida pela tradição, conforme narrado abaixo:

[...] Não há uma única regra, ainda que plausível e solidamente fundada na epistemologia, que não seja violada em algum momento. [...] Tais violações [...] são necessárias para o progresso. [...] [Pois] dada qualquer regra, não importa quão "fundamental" ou "racional", sempre há circunstâncias em que é aconselhável não apenas ignorá-la, mas adota a regra oposta ${ }^{36}$.

Resta, pois um único procedimento: vale tudo. “[...] Há apenas um princípio que pode ser defendido em todas as circunstâncias e em todos os estágios do desenvolvimento humano. É o princípio de que tudo vale"37.

Acertadamente, referenciando-se ao que afirma ser o acerto de Feyerabend, comenta Omnés:

Quanto ao objetivo que conferimos ao método, ele não poderia

\footnotetext{
33 FEYERABEND, P. Contra o método, p. 42.

${ }^{34}$ FEYERABEND, P. Contra o método, p. 31, grifos do autor.

${ }^{35}$ FEYERABEND, P. Contra o método, p. 40, grifo do autor.

${ }^{36}$ FEYERABEND, P. Contra o método, p. 37-38.

37 FEYERABEND, P. Contra o método, p. 42.
} 
ser, mais uma vez, um código de comportamento que dê garantia de chegar a descobertas: adotem-no e ficarão satisfeitos, ou seu dinheiro de volta. De fato, é perfeitamente claro que a posse de um método permitisse revelar a intimidade do Real pressuporia, e algum modo, um conhecimento do Real já quase perfeito. Não existe método para traçar de antemão um itinerário em terra desconhecida. É nesse argumento muito simples que me convence a crítica de Feyerabend e, em parte, justa, embora óbvia. Os exemplos que ele dá confirmam-na, em compensação, de maneira concreta, e podemos, pois, abandonar essa ideia outrora atraente e hoje caduca ${ }^{38}$.

Assim, percebe-se que a epistemologia de Feyerabend tende ao irracionalismo, ou seja, ao postulado de que a razão, por si só, especialmente através da criação de mecanismos ou métodos apriorísticos de identificação do real, não o é capaz de fazê-lo com sucesso.

\section{Relação entre as concepções epistemológicas: o irracionalismo}

Vistas a duas concepções epistemológicas de cada filósofo, se faz mister traçar, mesmo ainda como uma hipótese, haja visto se tratar de projeto de pesquisa, um paralelo identificando, senão todos os elementos que aproximam e que distanciam tais concepções, mas ao menos identificando que a conclusão a que cada uma, ao seu modo, chega, parece mostrar um mesmo caminho: o irracionalismo enquanto teoria epistemológica, posterior à época da racionalidade, ou seja, o Iluminismo.

Por um lado, Schopenhauer, ao criticar a filosofia do absoluto de Hegel, defende que não é possível à racionalidade humana conceber, entender e/ou explicar o real, uma vez que o real é constituído de algo que, ao menos abstratamente sob a forma de conceitos, não pode ser abstraído, mas tão somente intuído. Ele defende uma espécie de conhecimento espontânea e, com isto, demonstra o quanto inócua é a tentativa racional de estabelecer caminhos ou métodos que possibilitem tal conhecimento.

Por outro lado, Feyerabend, seguindo tradição da filosofia da ciência, postula que as grandes descobertas científicas, por surgirem na história e levando

38 OMNÉS, R. Filosofia da ciência contemporânea, p. 273. 
em consideração o contexto cultural de cada povo, não foram provocados, em sua maioria, pela observância de métodos rigorosos e definidos aprioristicamente, mas especialmente descobertos para dado campo de estudo. Sendo assim, não é possível, segundo ele, estabelecer métodos universais e absolutos que possam conduzir a racionalidade humana ao conhecimento do real. E quando tal acontece, estes nada mais são do que imposições que objetivam muito mais a manutenção das relações de poder do que a verdadeira busca do real.

Percebe-se, então, a proximidade que tais filósofos possuem, uma vez que as conclusões às quais chegaram, em momentos históricos distintos e com provocações diferentes, são assemelhadas.

\section{Referências bibliográficas}

ABBAGNANO, Nicola. Dicionário de filosofia. 3. ed. São Paulo: Martins Fontes, 1998.

ALAIN, Roger. Vocabulário de Schopenhauer. São Paulo: Martins Fontes, 2013.

BARBOZA, Jair. Schopenhauer. Rio de Janeiro: Jorge Zahar, 2003.

Schopenhauer: a decifração do enigma do mundo. São Paulo: Moderna, 1997.

A metafísica do belo de Arthur Schopenhauer. São Paulo: Humanitas / USP, 2001.

CACCIOLA, Maria Lúcia M. O. Schopenhauer e a questão do dogmatismo. São Paulo: EDUSP, 1994.

CARDOSO, Renato César. A ideia de justiça em Schopenhauer. Belo Horizonte: Argumentum, 2008.

CARTWRIGHT, David E. Historical dictionary of Schopenhauer's philosophy. Toronto: Scarecrow, 2005.

FEYERABEND, Paul. Contra o método. Tradução Cézar Augusto Mortari. São Paulo: UNESP, 2007.

. Adeus à razão. Tradução Vera Joscelyne. São Paulo: UNESP, 2011.

JANAWAY, Christopher. Schopenhauer. Tradução Adail Ubirajara Sobral. São Paulo: Loyola, 2003.

. The Cambridge companion to Schopenhauer. Cambridge: Cambridge Univesity, 1999.

KUHN, T. A estrutura das revoluções científicas 8. ed. São Paulo: Perspectiva, 2003.

OMNÉS, Roland. Filosofia da ciência contemporânea. São Paulo: UNESP, 1996. 
PERNIN, Marie-José. Schopenhauer: decifrando o enigma do mundo. Tradução Lucy Magalhães. Rio de Janeiro: Jorge Zahar, 1995.

POPPER, K. R. A lógica da pesquisa científica. Tradução Leonidas Hegenberg e Octanny Silveira da Mota. 2. ed. São Paulo: Cultrix; EDUSP, 1975.

RAMIREZ, Edgar Serna. El papel que tiene La intuición y el descubrimiento em La epistemoligía de Schopenhauer. In: XVII CONGRESSO DA SOCIEDADE INTERAMERICANA DE FILOSOFIA, 2013, Livro de resumos, Salvador: Quarteto, 2013, p. 157.

SAFRANSKI. Rüdiger. Schopenhauer e os anos mais selvagens da filosofia: uma biografia. Tradução William Lagos. São Paulo: Geração Editorial, 2011.

SCHOPENHAUER, Arthur. O mundo como vontade e como representação. Tomo I. 2. ed. Tradução Jair Barboza. São Paulo: UNESP, 2015a.

O mundo como vontade e como representação. Tomo II. Tradução Jair Barboza. São Paulo: UNESP, 2015b.

La cuadruple raíz del principio de razón suficiente. Tradução Eduardo Ovejero y Maury. Buenos Aires: Losada, 2008. (Biblioteca de obras maestras del pensamiento, 82).

Sobre a filosofia e seu método. Tradução Flamarion Caldeira Ramos. São Paulo: Hedra, 2010.

Recebido: $17 / 12 / 15$

Received: $12 / 17 / 15$

Aprovado: $25 / 04 / 16$

Approved: 04/25/16 